\title{
Can the lymph node reactivity pattern in the pNO neck analysis provide any additional prognostic information in patients with laryngeal squamous cell carcinoma?
}

\author{
A análise do padrão de reatividade linfonodal no pescoço pNO pode fornecer alguma \\ informação prognóstica adicional em pacientes com carcinoma epidermoide de laringe?
}

\author{
Gabriel Manfro ${ }^{1}$, Claudio Cernea ${ }^{2}$, Paulo Antônio Silvestre de Faria ${ }^{3}$, Fernando Vaz Agarez ${ }^{4}$, \\ Fernando Luiz Dias ${ }^{5}$, Roberto Araújo Lima ${ }^{6}$, Lenine Garcia Brandão ${ }^{7}$
}

\begin{abstract}
Objective: To evaluate the influence of lymph node reactivity on recurrence and survival rates in a population of pT3 or pT4 pNO patients with laryngeal squamous cell carcinoma. Methods: Between 2002 and 2005, 105 patients with LSSC underwent total laryngectomy with bilateral selective neck dissection including levels II, III and IV. Most (69) received PO radiotherapy. All pathological specimens were either pT3 or pT4, and all necks were pNO. All lymph nodes were analyzed and their reactivity status were classified as the following four patterns: follicular hyperplasia associated with humoral response, paracortical hyperplasia associated with cellular response, sinus histiocytosis with no association with specific immune response, or normal lymph node. Only the first two patterns were considered stimulated, whereas the last two were considered non-stimulated. The most prevalent pattern in a particular neck specimen was considered for the analysis of recurrence and survival. Results: The total number of lymph nodes studied was 3,648 , with an average of 34.7 lymph nodes/neck specimens. The most frequent lymph node reactivity patterns were sinusal histiocytosis ( 50 cases), paracortical hyperplasia ( 35 cases), and follicular hyperplasia (20 cases). There was no statistical association of these individual patterns with recurrence rate $(p=0.98)$ or mortality $(p=0.49)$. However, there was a statistically significant association between paracortical hyperplasia pattern (related to cellular lymph node immunity) and improved five-year survival (76 versus 60\%; log-rank $=0.05)$. Conclusions: There was a positive correlation between stimulated cellular lymph node pattern and improved 5-year survival rate in patients with pNO laryngeal squamous cell carcinoma, suggesting the indication of adjuvant treatment for those individuals
\end{abstract}

with decreased immune response, even in the absence of pathologic metastases detected by the usual methods.

Keywords: Head and neck neoplasm; Carcinoma, squamous cell; Laryngeal neoplasm/immunology; Lymph node excision; Lymph node excision/adverse effects; Lymph node excision/mortality; Neoplasm recurrence, local; Neck dissection

\section{RESUMO}

Objetivo: Avaliar a importância da reatividade linfonodal na recidiva e mortalidade em pacientes com carcinoma epidermoide de laringe estagiados como pT3 ou pT4 pNO M0. Métodos: Entre 2002 e 2005, foram selecionados 105 pacientes matriculados na Seção de Cirurgia de Cabeça e Pescoço do Instituto Nacional de Câncer (INCA) com o diagnóstico de carcinoma epidermoide de laringe, com estágio III ou IV. A radioterapia foi indicada em 69 casos. Todos os pacientes foram estagiados como pT3 ou pT4 e pNO. Todos os linfonodos ressecados foram analisados e classificados conforme os quatro padrões de reatividade linfonodal: hiperplasia folicular associada à resposta imune humoral, hiperplasia paracortical associada à resposta imune celular, histiocitose sinusal sem relação com resposta imune específica, e linfonodo normal. 0 s dois primeiros padrões são definidos como linfonodos estimulados e os dois últimos como linfonodos nãoestimulados. 0 padrão linfonodal mais frequente em cada paciente foi considerado para a análise da relação com a recidiva e mortalidade. Resultados: Foi analisado um total de 3.648 linfonodos, com média de 34,7 linfonodos por paciente. 0 padrão de reatividade mais

\footnotetext{
Study carried out at Instituto Nacional do Câncer - INCA, Rio de Janeiro (RJ), Brazil.

${ }^{1}$ Post-graduate student in Sciences from the Universidade de São Paulo (USP) and Instituto Nacional de Câncer (INCA) - Joaçaba (SC), Brazil.

${ }^{2}$ Postdoctorate degree; Lecturer of Head and Neck Surgery of the Faculdade de Medicina of Universidade de São Paulo - USP, São Paulo (SP), Brazil.

${ }^{3}$ Head of the Department of Pathology of Instituto Nacional de Câncer - INCA, Rio de Janeiro (RJ), Brazil.

${ }^{4} \mathrm{MD}$ of the Department of Pathology of Instituto Nacional de Câncer - INCA, Rio de Janeiro (RJ), Brazil.

${ }^{5}$ Head of the Department of Head and Neck Surgery of Instituto Nacional de Câncer - INCA, Rio de Janeiro (RJ), Brazil.

${ }^{6}$ Full professor of the Department of Head and Neck Surgery of Instituto Nacional de Câncer - INCA, Rio de Janeiro (RJ), Brazil.

${ }^{7}$ Postdoctorate degree; Lecturer of Head and Neck Surgery of the Faculdade de Medicina of Universidade de São Paulo - USP, São Paulo (SP), Brazil

Corresponding author: Gabriel Manfro - Rua Salgado Filho, 394, 301 - Centro - CEP 89600-000 - Joaçaba (SC), Brazil - Tel.: 49 3522-5195 - e-mail: gbmanfro@yahoo.com.br

Received on Jul 27, 2009 - Accepted on Dec 18, 2009
} 
frequente foi a histiocitose sinusal (50 casos), seguido da hiperplasia paracortical (35 casos) e da hiperplasia folicular (20 casos), sendo esses padrões sem relação com a recidiva $(p=0,98)$ ou mortalidade $(p=0,49)$. No entanto, 0 estímulo da imunidade celular relacionada à hiperplasia paracervical apresentou relação com significância estatística com melhor sobrevida global em cinco anos (76 versus $60 \%$; log-rank $=0,05)$. Conclusões: houve correlação positiva entre o padrão de estímulo da imunidade celular e o aumento da sobrevida em cinco anos em paciente pNO com carcinoma epidermoide de laringe sugerindo a indicação de tratamento adjuvante em casos que apresentarem diminuição da imunidade celular mesmo na ausência de metástases patológicas detectadas pelos métodos habituais.

Descritores: Neoplasias de cabeça e pescoço; Carcinoma de células escamosas; Neoplasias laríngeas/imunologia; Excisão de linfonodo; Excisão de linfonodo/efeitos adversos; Excisão de linfonodo/ mortalidade; Recidiva local de neoplasia; Esvaziamento cervical

\section{INTRODUCTION}

Neck metastases represent one of the worst prognostic factors if compared to $\mathrm{pN} 0$ patients, especially when there is lymph node leakage ${ }^{(1)}$. This makes the neck a site of special attention considering the treatment of neoplastic laryngeal disease ${ }^{(2)}$.

Even when there are no clinically detectable lymphatic metastases, the prophylactic treatment of neck nodal chains is advocated in patients with $\mathrm{T} 3$ and T4 tumors submitted to surgery, because of the high incidence of occult metastases in this group of patients, which can occur in up 55\% of level III cases of neck lymphatic drainage ${ }^{(3)}$.

Approximately $70 \%$ of cases of laryngeal cancer submitted to elective neck dissection did not have metastases in the pathology study (pN0)(3); notwithstanding, in some cases, resection with free margins associated with prophylactic neck dissection does not rule out disease recurrence, and such behavior may be explained by understanding the relation between this disease and the host immune system.

Usually, the absence of lymph node metastases in the specimens removed during neck dissection does not indicate adjuvant treatment. Nonetheless, a more detailed study of these lymph nodes can result in important prognostic information which helps in indication of adjuvant treatment.

The lymph node reactivity study, indirectly checking the immune response of the host, started in cases of breast cancer, and is no longer used in this type of disease. However, this relationship has been more recently described to analyze malignant head and neck tumors, gathering relevant information about disease prognosis from data often times neglected by surgeons, such as lack of lymphatic metastases in the lymphadenectomy specimen $^{(4-6)}$.
Standardization and reproduction of these results in larger samples is necessary in order to indicate or not lymph node reactivity assessment in order to do a prognostic evaluation of laryngeal and head and neck cancer $^{(7)}$.

\section{OBJECTIVE}

To assess the importance of lymph node reactivity in mortality of patients with pNO MO pT3 or pT4 laryngeal squamous cell carcinoma (LSCC).

\section{METHODS}

A total of 105 patients enrolled at the Head and Neck Division of the Instituto Nacional de Câncer (National Cancer Institute, INCA) diagnosed with stages III or IV laryngeal squamous cell carcinoma was selected. The study was based on the Sistema Hospitalar Integrado (SHI) of INCA Database, with information collected between 2002 and 2005, from patients submitted to total laryngectomy and selective neck dissection levels II, III and IV, bilaterally, associated or not to radiotherapy - staged by the 2002 American Joint Committee on Cancer (AJCC), as pT3 or pT4, pN0, M0. Indication for radiotherapy was always based on the primary tumor, and it was carried out in most pT4 tumors and those pT3 with large tumoral volume, subjectively assessed by the patient's head and neck surgeon. The mean follow-up period was 46 months, range of 3 to 84 months.

All slides and paraffin blocks with neck lymph node specimens from the group of selected patients were separated. All resected and dissected lymph nodes were examined by the same pathologist (PASF) and by the current paper's researcher, and classified according to the region of the predominant lymph node. Such classification was based on the work of Tsakrakliddes et al. ${ }^{(8)}$, who divided them into four classes: follicular hyperplasia $(\mathrm{FH})$, paracortical hyperplasia $(\mathrm{PH})$, sinus histiocytosis $(\mathrm{SH})$ and normal lymph node.

Hyperplasia is the increase in cellularity and in the area occupied by an activated lymph node compartment. The normal lymph node histology was the parameter used to identify which compartment stood out when compared to others.

The lymph node from each patient was analyzed under light microscopy with the lower magnification lens (100 times). At this point, we scanned a larger area of the lymph node, and it was possible to identify the predominant region or the proportion of regions characterizing a normal lymph node (Figure 1). The larger magnification (400 times) on light microscopy was used to confirm the hyperplasia pattern. 


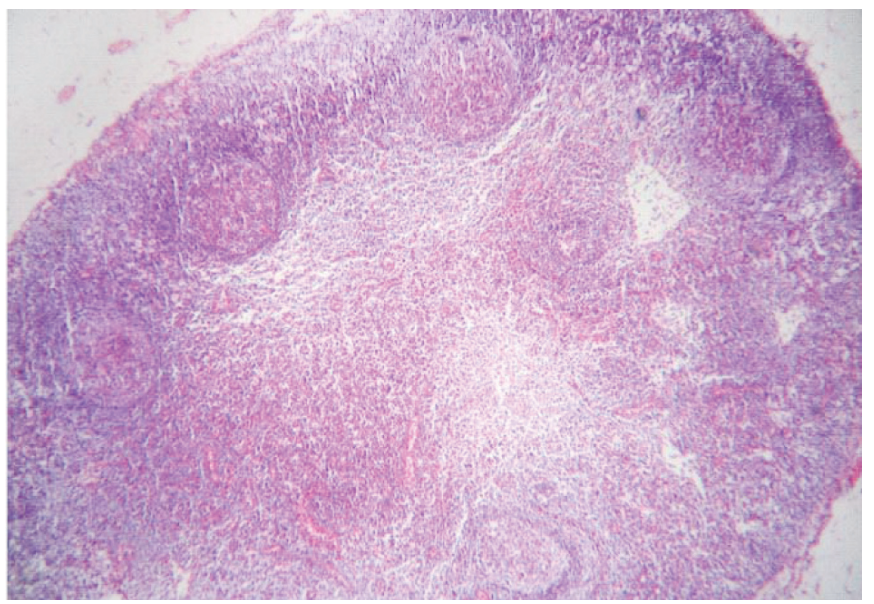

Figure 1. Normal lymph node showing proportional lymph node regions (magnification $40 \mathrm{x}$ )

The predominant hyperplasia pattern of each lymph node was written down and, after analyzing all lymph nodes from each case, the first and second most frequent hyperplasia patterns were identified.

During the microscopic analysis of each lymph node, we first analyzed the cortical and medullar regions. Within the cortical region, we identified the external cortex, located right below the subcapsular sinus, where it was possible to identify the lymphoid follicles, rich in B lymphocytes. The lymphoid follicles are broken down into primary and secondary. The primary type corresponds to the non-stimulated follicles, where we can identify a dense and homogeneous aggregate of small lymphocytes. The secondary follicle is characterized when there is a response to antigenic stimuli, forming a germinal center within the primary follicle. The germinal center core is characterized by a heterogeneous cell aggregate, containing large and small lymphocytes, and also macrophages. In this region, we can also see mitotic cells, since this is an area of intense cell proliferation. When this region predominated in the lymph node, it was characterized as FH (Figure 2).

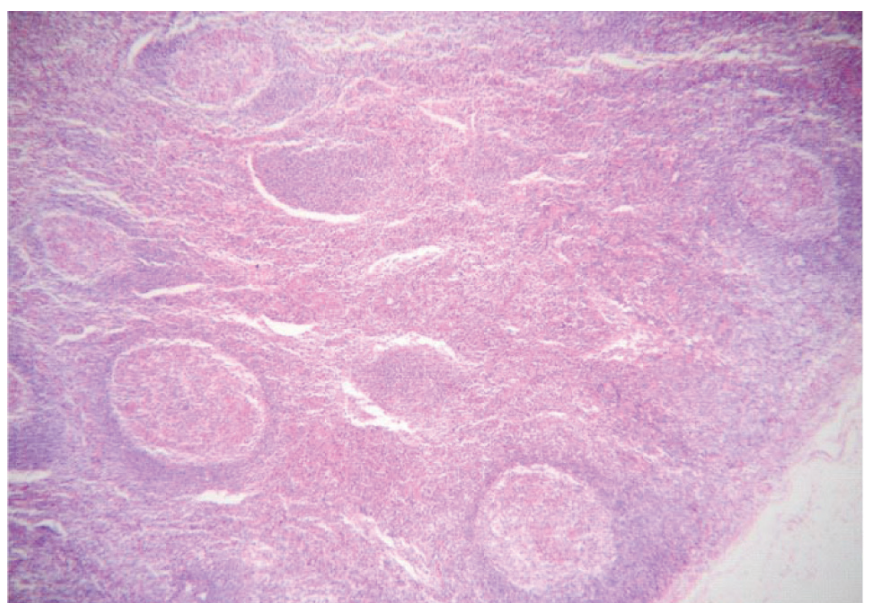

Figure 2. Stimulated lymph node with predominance of the cortical region, showing stimulated follicles (magnification 100x)
Looking at the lymph node core, after the external cortex, we identified the deep cortex, or paracortical region. This region is made up predominantly by TCD4+ lymphocytes. It is a compartment difficult to outline, it can extend within the lymphoid follicles all the way to the subcapsular sinus, and the lymph node postcapillary venules are used to characterize this lymph node region. When this lymph node region predominated over the others, it was called PH (Figure 3).

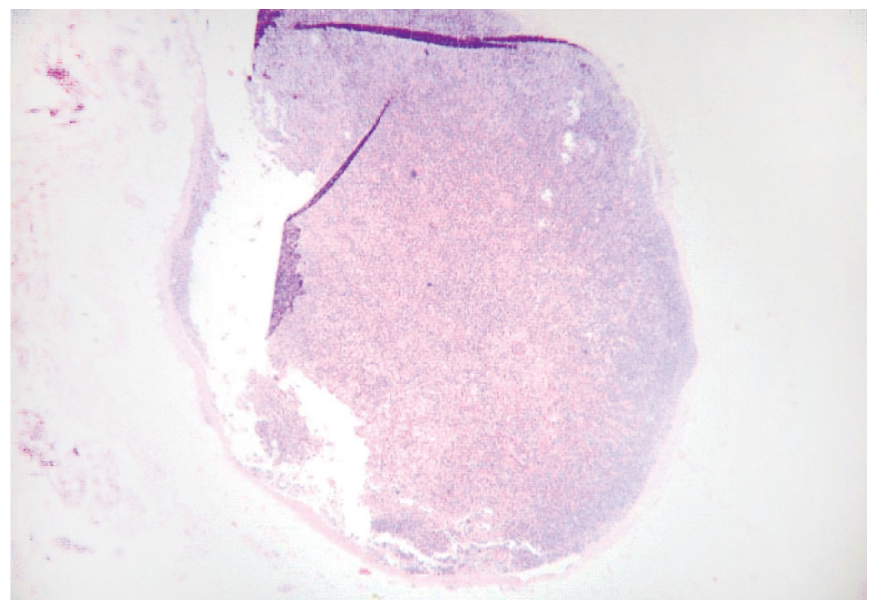

Figure 3. Lymph node showing predominance of the paracortical region (predominance of the cortical region)

In the most central region of the lymph node, there is the medullar region, where we identify the medullar cords, which are interspersed by the medullar sinuses, rich in histiocytes and macrophages, there may also be eosinophils, plasmocytes, red blood cells and neutrophils. It is in this compartment that the antigens present in the lymph are filtered and presented to the cortical lymphocytes. When we see a dilation of the medullar sinuses, this region can extend to beyond the medullar region, characterizing the SH (Figure 4).

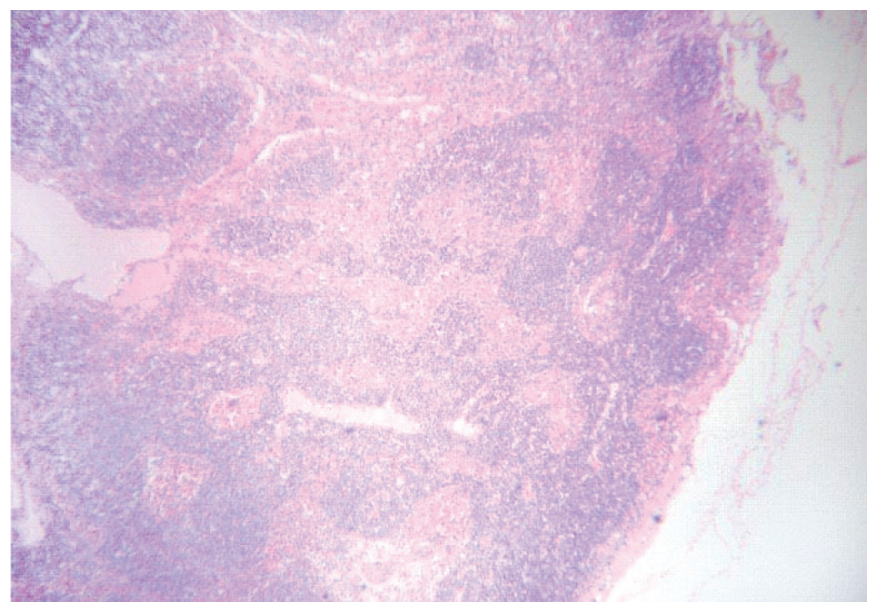

Figure 4. Picture of a lymph node showing predominance of the nodal sinus region, with histiocytosis occupying up to the lymph node cortex (magnification $40 \mathrm{x}$ ) 
In $60 \%$ of cases, there was agreement between the two analyses. The remaining $40 \%$ of disagreement between the researcher and the pathologist were discussed together until a consensus was reached about the region where the lymph nodes predominated.

After defining the lymph node reactivity pattern, the 105 patients were divided according to the immune response (cellular or humoral) present in each case and according to the presence or absence of the immune stimulus. This classification was conducted as follows: the cases in which there was a predominance of $\mathrm{FH}$ or PH were considered stimulated lymph nodes and the cases in which the predominance was of SH or normal lymph nodes were considered as not stimulated. The cases in which the predominance was of $\mathrm{FH}$ were considered of humoral immunity, and the cases in which the $\mathrm{PH}$ was more frequent were considered of cell immunity. When there was a predominance of $\mathrm{SH}$, it was considered the second most frequent pattern of hyperplasia, since $\mathrm{SH}$ is not associated to any specific type of immune response.

The lymph node hyperplasia pattern, the type of immunity stimulated and the presence or absence of an immune stimulus were associated to the disease-free survival and the overall survival in the group of patients studied.

For the statistical analysis we used the Epi-Info, version 3.4.3 software, from November 2007, using the $\chi^{2}$ test to calculate the $p$ value and, for the survival curve, we used the Kaplan-Meier method.

\section{RESULTS}

For this study, a total of 105 patients, 91 men and 14 women, were selected. The mean age in this group was 62.2 years, with a median of 61 years - the youngest patient was 38 years old and the oldest was 86 years old.

All patients were submitted to total laryngectomy with selective level II, III and IV bilateral neck dissection. In 69 cases $(65.7 \%)$, radiotherapy was associated to surgery because of the pT4 stage of disease in 59 cases and of tumor volume in 10 cases staged as pT3. The mean radiotherapy dose was $49.7 \mathrm{~Gy}$ - minimum dose of $45 \mathrm{~Gy}$ and maximum of $65 \mathrm{~Gy}$. The indication for radiotherapy did not influence recurrence or mortality, regardless of disease stage.

In the pathology analysis, 70 patients $(66.7 \%)$ were staged as pT4 and 35 patients $(33.3 \%)$ as pT3. All patients were staged as $\mathrm{pN} 0$, since this was one of the inclusion criteria for patients in this study, and the disease stage was directly associated with tumor size. In the statistical analysis, the tumor size in the pathology study $(\mathrm{pT})$ was not associated with recurrence $(\mathrm{p}=$
0.34), nonetheless, pT4 tumors had a higher tendency to present greater mortality $(\mathrm{p}=0.097)$.

When we analyzed lymph node reactivity in the group of patients studied, we noticed that the most frequent reactivity pattern of neck lymph nodes was $\mathrm{SH}$ ( 50 cases), followed by PH ( 35 cases) and FH ( 20 cases). In none of the cases there was predominance of normal lymph nodes.

The neck lymph node reactivity pattern was associated with disease recurrence and mortality. When we analyzed the three types of reactivity pattern separately, there was no prognostic relation of this variable with statistical significance, both when assessing recurrence $(\mathrm{p}=0.98)$ and when assessing mortality $(\mathrm{p}$ $=0.49)($ Table 1$)$.

Table 1. Relationship between lymph node reactivity pattern, recurrence and mortality, in 105 laryngeal squamous cell carcinoma patients, treated at the Instituto Nacional de Câncer (INCA) between 2002 and 2005

\begin{tabular}{lcccccc}
\hline \multirow{2}{*}{ Reactivity pattern } & \multicolumn{3}{c}{ Recurrence } & \multicolumn{3}{c}{ Death } \\
\cline { 2 - 7 } & No & Yes & Total & No & Yes & Total \\
\hline Follicular hyperplasia & 15 & 5 & 20 & 12 & 8 & 20 \\
Parafollicular hyperplasia & 27 & 8 & 35 & 26 & 9 & 35 \\
Sinus histiocytosis & 38 & 12 & 50 & 36 & 14 & 50 \\
p-value & & 0.98 & & & 0.49 & \\
\hline
\end{tabular}

When we divided the reactivity pattern according to stimulated immunity, if humoral or cellular, death by the disease was more frequent in patients whose immune response was humoral stimulated, and this association had statistical significance $(\mathrm{p}=0.025)$. When associated with recurrence, the type of immune response did not show any prognostic association $(\mathrm{p}=0.17)$ (Table 2$)$.

Table 2. Relationship between type of stimulated immunity, recurrence and mortality, in 105 patients with laryngeal squamous cell carcinoma, treated at the Instituto Nacional de Câncer (INCA) between 2002 and 2005

\begin{tabular}{lcccccc}
\hline \multirow{2}{*}{ Stimulated immunity } & \multicolumn{3}{c}{ Recurrence } & \multicolumn{3}{c}{ Death } \\
\cline { 2 - 7 } & No & Yes & Total & No & Yes & Total \\
\hline Humoral immunity & 31 & 13 & 44 & 26 & 18 & 44 \\
Cell immunity & 49 & 12 & 61 & 48 & 13 & 61 \\
p-value & & 0.17 & & & 0.025 & \\
\hline
\end{tabular}

Analyzing the five-year disease-free survival curves according to the stimulated immunity, in cases in which the humoral immunity (associated with $\mathrm{FH}$ ) was stimulated, there was a survival of $67 \%$ compared to $77 \%$ in the group with stimulated cellular immunity (associated with $\mathrm{PH}$ ); nonetheless, this difference did not show statistical significance $(\log$-rank $=0.26)$.

When we analyzed overall survival curves, the group with stimulated cellular immunity had better prognosis, with $76 \%$ of patients being alive after five 
years of treatment, compared to the group with humoral immunity, in which only $60 \%$ of patients reached five-year survival, and this difference was statistically significant $(\log$-rank $=0.05)($ Figure 5$)$.

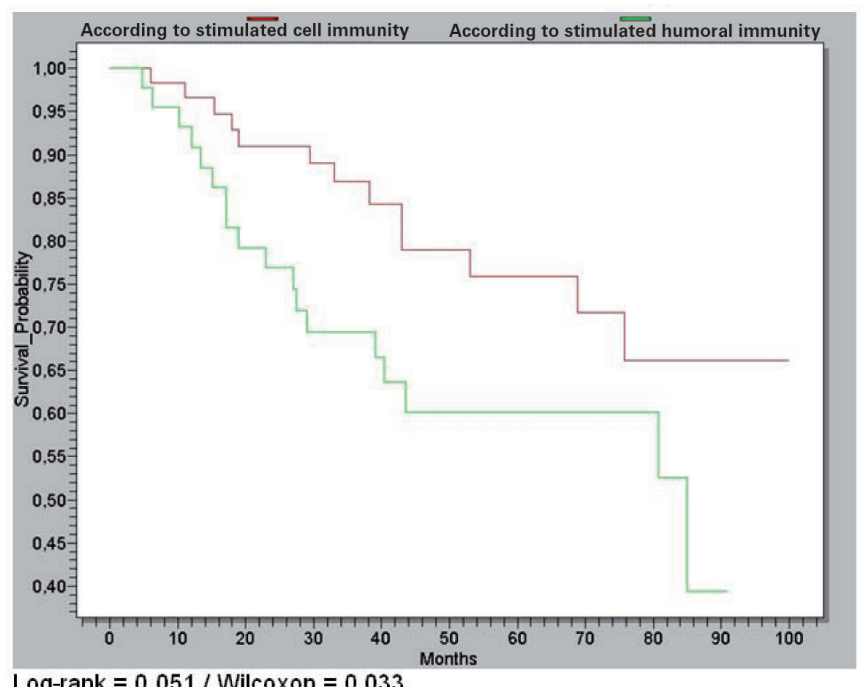

Figure 5. Overall survival curves according to stimulated immunity, in 105 patients with laryngeal squamous cell carcinoma, treated at the Instituto Nacional de Câncer (INCA) between 2002 and 2005

Separating the patients into two groups according to the prevalence of immunologically-stimulated lymph nodes (FH or parafollicular hyperplasia) and non-stimulated lymph nodes ( $\mathrm{SH})$, and compared with recurrence and mortality, there was no statistical significance (Table 3).

Table 3. Relationship between presence of immunological stimulus in lymph nodes, recurrence and death, in 105 patients with laryngeal squamous cell carcinoma, treated at the Instituto Nacional de Câncer (INCA) between 2002 and 2005

\begin{tabular}{lcccccc}
\hline \multirow{2}{*}{ Stimulated lymph nodes } & \multicolumn{3}{c}{ Recurrence } & \multicolumn{3}{c}{ Death } \\
\cline { 2 - 7 } & No & Yes & Total & Yes & No & Total \\
\hline No & 38 & 12 & 50 & 36 & 14 & 50 \\
Yes & 42 & 13 & 55 & 38 & 17 & 55 \\
p-value & & 0.57 & & & 0.45 & \\
\hline
\end{tabular}

\section{DISCUSSION}

The malignant tumor evolution results from the opposition of tumor aggressiveness factors and host resistance $^{(9)}$. Studies based on this interaction between tumor and hosts have gained popularity in head and neck cancer ${ }^{(10)}$.

The host has some immune defenses against some malignant diseases. Based on this, parameters which reflect the host defense may predict survival ${ }^{(11)}$.

Analyzing this tumor-host relation, few studies presented homogeneous groups submitted to the same type of treatment ${ }^{(12)}$.
The patient is not merely a passive participant in tumor growth and carcinogenesis. Reactive lymphadenitis, found in some patients with malignant tumors, is the very proliferation of lymphatic tissue and the active immune response of the host against the malignant tumor ${ }^{(5)}$.

The use of lymph node reactivity as a prognostic factor faces the difficulty to properly classify different patients with heterogeneous reactivity. Hyperplastic lymph nodes are frequently found during neck dissections, with still unclear clinical meaning ${ }^{(7)}$.

The analysis of lymph node reactivity is very difficult, and one of the main reasons for that is the fact that lymph node analysis is more subjective than objective $^{(13)}$. Lymph node reactivity can vary according to the distance between the tumor and the lymph nodes, infection, patient nutrition and subjectivity in analyzing the lymph nodes ${ }^{(7)}$.

The assessment of lymph node reactivity aims to indirectly assess the host immune response facing a malignant tumor.

Reactive lymphadenitis, in cancer patients, is basically the host immune response to the malignant tumor. Contrasting to that, a normal lymph node or one with depletion represents a morphological manifestation of the lymphatic system loss of reactivity against tumor development, and the stimulated lymph node as a factor of favorable prognosis ${ }^{(5)}$.

In this series, of the 105 cases, $50(47.6 \%)$ had the $\mathrm{SH}$ pattern in most of the resected lymph nodes. The second most frequent pattern was the presence of $\mathrm{PH}$, prevailing in 35 cases $(33.3 \%)$. FH was the most common pattern found in 20 patients $(19.1 \%)$. FH was also the most frequent reactivity pattern found in the lymph nodes from the studies by Cernea et al. ${ }^{(4)}$, in which $13(50 \%)$ of 26 patients with epidermoid carcinoma of the mouth presented the prominence of the primary follicles in the lymph node cortex. In this study, the second most frequent pattern was $\mathrm{SH}$ and the group of patients with stimulated lymph nodes (FH and $\mathrm{PH}$ ) had lower disease recurrence (23\% of cases) and better disease-free survival in five years $(73 \%)$, and such results had statistical significance $(\mathrm{p}<0.05)$.

The lymph node reactivity pattern did not have statistically significant relation with disease recurrence nor with mortality.

In 1985, Ring et al. ${ }^{(14)}$ studied 43 patients with mouth floor cancer. In that study, $\mathrm{SH}$ was associated with better prognosis when compared to patients with PH. In 1993, Patt et al. ${ }^{(15)}$ found similar results. A total of 48 laryngeal cancer patients were studied; the group with lymph node metastasis found in the pathology study presented $\mathrm{SH}$ in most of the lymph nodes and had better survival $(\mathrm{p}=0.007)$. 
In 1953, studying breast cancer, Black et al. ${ }^{(16)}$, pioneers in the study of lymph node reactivity, discovered that patients with a greater degree of lymph node histiocytosis in specimens taken from axillary lymph node dissections also had better survival.

Different results are also described in the literature. In 1971, Bennet et al. ${ }^{(17)}$ studied 84 patients with larynx and hypopharynx cancer, and noticed that those with $\mathrm{FH}$ in the groups of $\mathrm{pN}+$ patients and with differentiation levels III or IV had better prognosis.

In 1992, Fernández-Nogueras et al. ${ }^{(18)}$ did not find associations between lymph node reactivity patterns and five-year survival in patients with laryngeal cancer, likewise Amar et al. ${ }^{(7)}$, who studied 19 patients with occult primary tumor and did not find association between lymph node reactivity and prognosis in this group of patients.

Regional lymph nodes are the first components of the immune system to have contact with tumor cells and their products. Thus, the microscopic aspect of the drainage lymph node is important to understand the immune system controlling the malignant cells ${ }^{(18-}$ 19). The lymph nodes with FH or PH showed indirect signs of immune response against the tumor. $\mathrm{SH}$, when predominant in the lymph node, corresponds to proliferation of macrophages, which are non-specific cells of cellular or humoral immunity ${ }^{(13)}$.

In our series, when we divided the patients into two groups according to the lymph node stimulus (one made up of individuals in whom most of the resected lymph nodes had $\mathrm{FH}$ or $\mathrm{PH}$, that is, stimulated lymph nodes, and another group formed by patients in whom most lymph nodes had a predominance of $\mathrm{SH}$, that is, non-stimulated), when compared to recurrence and mortality, there was no statistical significance.

In 2003, Starska et al. ${ }^{(20)}$ studied 179 cases of laryngeal cancer, concluding that patients with lymph nodes without signs of immune stimulus had a worse prognosis, with statistical significance.

Berlinger et al. ${ }^{(11)}$ analyzed 84 patients with head and neck carcinoma, and found a five-year survival significantly higher in the group of patients with signs of immune response in the pathology study of the resected lymph nodes, that is, stimulated lymph nodes.

In 1987, Pohris et al. ${ }^{(13)}$ assessed 107 patients with laryngeal cancer at different stages, varying from stage II through IV. This group reported a five-year diseasefree survival better than the group of patients with stimulated lymph nodes, that is, with FH or PH.

The lymph node paracortical region is the main lymphocyte proliferation site in the cell-mediated immune response, and this region is present in a higher number of lymphoid cells ${ }^{(20-22)}$.
The germinal centers are always associated with humoral immunity - in other words, with production of antibodies $^{(20-22)}$.

SHhas a predominance of macrophages and histiocytes, not specific of any type of immune response ${ }^{(13)}$.

If we characterize the $\mathrm{PH}$ as cellular immune response and $\mathrm{FH}$ as humoral immune response, and we analyze this type of immune response present in the lymph node during tumor development, the group of patients with signs of humoral response in most lymph nodes presented a greater mortality, with statistical significance $(p=0.025)$ compared to the patients with cellular immune response signs. Disease recurrence did not present statistical significance in relation to the type of immune response against the tumor; there was a tendency of greater recurrence in cases of humoral immune response, observed in $41.9 \%$ of cases, as compared to $24.4 \%$ of recurrence in cases of cellular immune response $(\mathrm{p}=0.17)$.

Associating the pattern of lymph node reactivity with the type of recurrence, there was a very homogeneous distribution between the type of hyperplasia and the disease recurrence site, having no statistically significant association in this analysis.

\section{CONCLUSIONS}

Patients with signs of cellular immunity stimulus (PH) had lower mortality when compared to patients with a predominance of humoral immune response $(\mathrm{FH}$; $\mathrm{p}=0.025$ ).

The lymph node reactivity pattern analyzed alone did not show association with disease recurrence or with mortality.

The overall five-year survival rate was significantly lower in patients with humoral immune response activation (60\%), compared to the overall survival of patients with cellular immune response activation $(76 \%)(\log -$ rank $=0.05)$.

\section{REFERENCES}

1. Oosterkamp S, de Jong JM, Van denEnde PL, Manni JJ, Dehing-Oberije C, Kremer B. Predictive value of lymph node metastases and extracapsular extension for the risk of distant metastases in laryngeal carcinoma. Laryngoscope. 2006;116(11):206770.

2. Shah JP, Medina JE, Shaha AR, Schantz SP, Marti JR. Cervical lymph node metastasis. Curr Probl Surg. 1993;30(3):284-335.

3. Shah JP. Patterns of cervical lymph node metastasis from squamous carcinomas of the upper aerodigestive tract. Am J Surg. 1990;160(4):405-9.

4. Cernea CR, Montenegro F, Castro I, Cordeiro A, Gayotto L, Ferraz A, et al. Prognostic significance of lymph node reactivity in the control of pathologic negative node squamous cell carcinomas of the oral cavity. Am J Surg. 1997;174(5):548-51.

5. Stankiewicz $\mathrm{C}$. Prognostic significance of lymph node reactivity in patients with laryngeal carcinoma. Eur Arch Otorhinolaryngol. 1994;251(7):418-22. 
6. Gallo O, Boddi V, Bottai GV, Franchi A, Storchi OF. Prognostic significance of clinically false positive cervical lymph nodes in patients with laryngeal carcinoma. Cancer. 1995;75(5):1077-83.

7. Amar A, Rosa MP, Rapoport A, Magalhães MR, Carvalho MB. Reatividade linfonodal com metástase cervical de tumor primário oculto - Estudo de 24 pacientes. Rev Col Bras Cir. 2001;28(3):193-7.

8. Tsakraklides V, Anastassiades OT, Kersey JH. Prognostic significance of regional lymph node histology in uterine cervical cancer. Cancer. 1973;31(4):860-8.

9. Burnet FM. Immunological aspects of malignant disease. Lancet. 1967;1(7501):1171-4.

10. Alberty J, Wardelmann E. Histomorphologic reaction patterns in cervical lymph nodes of different neck sites. Lymphology. 2001;34(2):77-83.

11. Berlinger NT, Tsakraklides V, Pollak K, Adams GL, Yang M, Good RA. Immunologic assessment of regional lymph node histology in relation to survival in head and neck carcinoma. Cancer. 1976;37(2):697-705.

12. Polyak K, Haviv I, Campbell IG. Co-evolution of tumor cells and their microenvironment. Trends Genet. 2009;25(1):30-8. Review.

13. Pohris, E, Eichhorn T, Glanz H, Kleinsasser 0 . Immunohistological reaction patterns of cervical lymph nodes in patients with laryngeal carcinomas. Arch Otorhinolaryngol. 1987;244(5):278-83.

14. Ring AH, Sako K, Rao U, Razack MS, Reese P. Immunologic patterns of regional lymph nodes in squamous cell carcinoma of the floor of the mouth. Am J Surg. 1985;150(4):461-5.
15. Patt BS, Close LG, Vuitch F. Prognostic significance of sinus histiocytosis in metastatic laryngeal cancer. Laryngoscope. 1993;103(5):498-502.

16. Black MM, Kerpe S, Speer FD. Lymph node structure in patients with cancer of the breast. Am J Pathol. 1953;29(3):505-21.

17. Bennet SH, Futrell JW, Roth JA, Hoye RC, Ketcham AS. Prognostic significance of histologic host response in cancer of the larynx or hypopharynx. Cancer. 1971;28(5):1255-65.

18. Fernández-Nogueras FJ, Fernández-Nogueras V, Esquivias López-Cuervo JJ. [Prognostic value of lymph node histologic pattern in epidermoid carcinoma of the larynx]. Acta Otorrinolaringol Esp. 1992;43(3);165-7.

19. Verastegui E, Morales R, Barrera JL, Müeller A, Guzman B, Meneses A, et. al. Immunological approach in the evaluation of regional lymph nodes of patients with squamous cell carcinoma of the head and neck. Clin Immunol. 2002;102(1):3747.

20. Starska K, Kulig A, Łukomski M. [Prognostic significance of sinus histiocytosis and lymphocyte predominance in lymph nodes of patients with laryngeal carcinoma]. Otolaryngol Pol. 2003:57(1):45-50.

21. Cottier H, Turk J, Sobin L. A proposal for a standardized system of reporting human lymph node morphology in relation to immunological function. J Clin Path. 1973;26(5):317-31.

22. Ferlito A, Polidoro F. Biological and prognostic implications of the morphologic aspects of immune reaction in lymph nodes draining head and neck cancers. $J$ Laryngol Otol. 1979;93(2):153-75. 